\title{
Nursing theories in palliative care investigation: a review
}

\begin{abstract}
Background: Palliative care needs are increasing worldwide. Although palliative care is an interdisciplinary approach, nurses play a central role in the team context. As it is necessary to clarify the unique contribution of nursing to palliative care, the current study aims to identify and analyze the nursing theories used in Palliative Care research. The methodology was a literature review of investigation articles published between 1994 and 2014 in the databases Pubmed, CINAHL, B-on, Cuiden, Scopus, Cochrane Library and Embase. Fifteen articles from 6 countries that used 10 different theories were found. The grand theory was the most used type of theory and the Humanistic Nursing Theory was the most used theory. We conclude that there is no consensus surrounding the utilization of one unique theory in Palliative Nursing. It is considered that the use of different theories in different contexts and different populations can contribute to a sustained reflection. There needs to be more studies developed in this context with a theoretical background.
\end{abstract}

Volume 2 Issue 4 - 2018

\author{
Alexandra Pereira, ${ }^{1,2}$ Amélia Ferreira, ${ }^{1,2}$ \\ José Martins, ${ }^{3}$ Céu Barbieri-Figueiredo $\mathrm{M}^{4}$ \\ 'Community Care Unit of Lousada, Portugal \\ ${ }^{2}$ Nursing Sciences Doctoral Program, Abel Salazar Institute of \\ Biomedical Sciences, Portugal \\ ${ }^{3}$ Nursing School of Coimbra, Portugal \\ ${ }^{4}$ Nursing School of Porto, Portugal
}

Correspondence: Alexandra Pereira, Community Care Unit of Lousada, Largo da Beneditina, 7, 4I50-I32, Porto, Portugal,Tel +35191 70076 18, Email alemnap@gmail.com

Received: June 30, 2018 | Published: August 03, 2018

Keywords: nursing theory, palliative care, hospice and palliative care nursing

\section{Introduction}

Palliative care is considered an essential component of any healthcare system. In spite of that, the access to this type of care is still inadequate in many countries. It is estimated that palliative care needs will continue to grow, as the rapidly aging of the population leads to increasingly complex health conditions. ${ }^{1}$ Palliative care is an approach that promotes and improves the quality of life of patients and their families facing problems associated with life-threatening illness, through the prevention and relief of suffering by means of early identification and accurate assessment and treatment of pain and other physical, psychosocial and spiritual problems. ${ }^{2}$ This is an interdisciplinary approach that involves patient, family and community into action. ${ }^{3}$ In fact, the practical and philosophical notion of an interdisciplinary team is crucial to provide quality palliative care. $^{4}$

Although the composition of palliative care teams varies depending on patient needs and available resources, the presence of a nurse is constant and constitutes the first link between team, patient and family, putting into practice the established healthcare plan in every context of care. ${ }^{5}$ Thus, nurses play a central role in palliative care, acting in the best interest of patients and their families and providing care on a continuous basis. ${ }^{6}$ The relationship established between patient and nurse is fundamental and provides an unique contribution to palliative care..$^{711}$ The link between palliative care and nursing is so narrow that many times it is said that palliative care is the epitome of good nursing practice. ${ }^{12}$ Therefore, there is a risk that the role of nursing in palliative care would be confused with a vague description of its interdisciplinarity, losing the sense and importance of nursing intervention. ${ }^{13}$ Some authors claim that too much emphasis in interdisciplinary research can dilute nursing knowledge and outshine the nursing role on planning and providing care. ${ }^{14}$

Lynch and collaborators claim that the multidimensional concept of quality of life requires a shared contribution of different disciplines and that identifying the singular contribution of each one is also essential to enrich the interdisciplinary focus of palliative care, assuring high quality care. ${ }^{15}$ Consequently, there is a growing need to affirm nursing in palliative care in theory, practice and research. The link between theory and research is characterized by a mutual and dynamic interaction in which research findings supports theory and theory provides questions and hypothesis to research. ${ }^{16}$ Fawcett says that the functions of a theory are to clearly specify conceptual models phenomena and to provide a specific structure to understand behaviors, situations and events. ${ }^{17}$ The current study aims to identify and analyze the nursing theories used in palliative care research.

\section{Methods}

This review was undertaken to identify palliative care research that used a nursing theory. These standard bibliographic databases were researched: PubMed, CINAHL, B-On, Cuiden, Scopus, Cochrane Library and Embase. A combination of the following search terms were used with the Boolean phrase 'and/or' in order to maximize the type and range of material captured by the search: ("palliative nursing" or "palliative care" or "terminal care" or "end-of-life care") and ("nursing theory" or "nursing model"). Publications that were based on opinion or commentary, editorials and conference abstracts were excluded. Publications were selected based on the following inclusion criteria: 1) Research relevant to palliative care; 2) Research that used at least one nursing theory; 3 ) Research published between January 1994 and December 2014. Duplicates were removed and then the titles and abstracts of publications returned in the database results were manually reviewed by two independent researchers in order to confirm the inclusion criteria. Then the researchers analyzed the full text articles and developed a list gathering data on year of publication, country where the research took place, methodology, nursing theory used and its application.

\section{Results}

A flow diagram about the selection of articles is detailed in Figure 1. Overall, 360 articles were identified. Ninety two articles 
were removed as they were duplicates. The titles and abstracts of the remaining 268 studies were reviewed. This resulted in 183 of studies being excluded as they did not meet the inclusion criteria. Eighty five articles were retrieved for full text examination. The final review included 15 articles studies that were published over the period under examination.

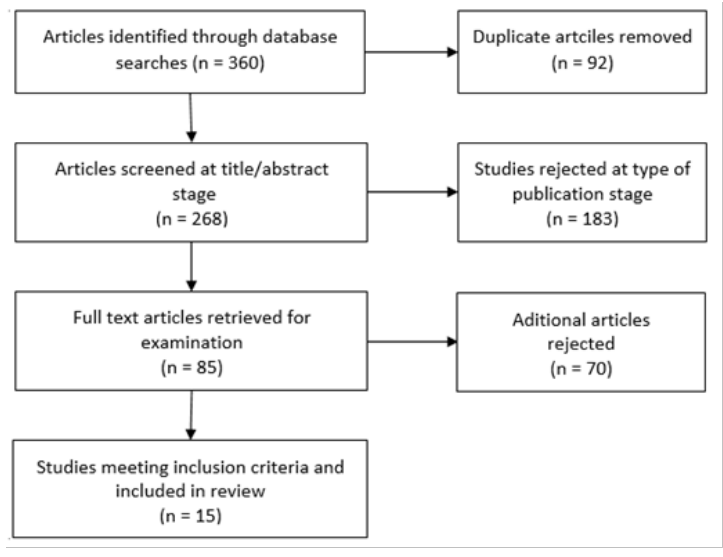

Figure I Selection and review process.

A summary of reviewed articles is presented in Table $1^{18-32}$

Only 4 articles had one single author and 11 articles were written by research teams composed by 2 to 6 elements. There was an upward trend in the number of studies published from 2005 to 2014 (80,0\%). The oldest article was published in 1995 and the most recent was published in 2014. There was an absence of articles in 1994, 1996, 1998 to 2000, 2002 to 2004 and 2011. Apart from that, one article was

Table I Summary of reviewed articles published every year, except for 2007 ( 3 articles) and 2005 ( 2 articles) (Figure 2). The authors of the articles were from 6 different countries. USA was the most represented country ( 6 articles), followed by Brazil (3 articles). We also found 2 articles from Sweden, 2 from the United Kingdom, 1 from Thailand and 1 from France (Table 2). In terms of research design, 13 articles $(86,7 \%)$ were qualitative in nature when compared to 2 articles $(13,3 \%)$ that were qualitative. The majority of articles studied one type of population, only 2 articles studied two different populations. Patients were the most studied population (9 articles), followed by nurses ( 6 articles) and family caregivers (2 articles). One article analyzed health records.

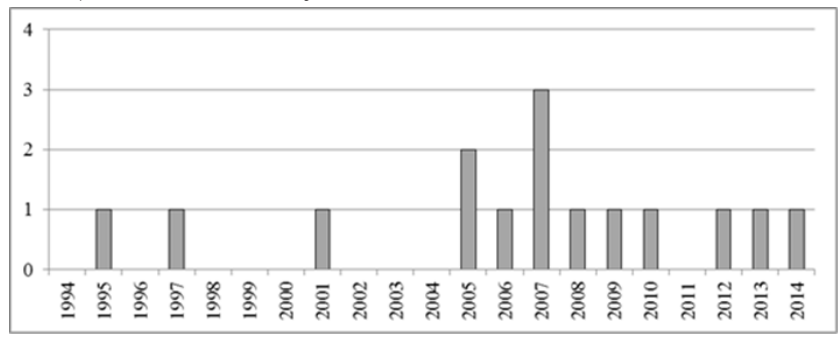

Figure 2 Review results distributed by publication year(n).

Regarding the nursing theory, a great variety was used. The 15 articles were distributed by 10 different theories. The most used theory was the humanistic nursing theory ( 4 articles), followed by man living health theory ( 3 articles). The other theories were used once, one in each article (Table 3). In terms of type of theory, 10 articles used a grand theory, 4 articles used a middle-range theory and 1 article used a conceptual model. There was an upward trend in the application of the theory as a provider of framework for data analysis and interpretation (11 articles) and in 9 articles the theory provided the philosophical underpinnings of the study.

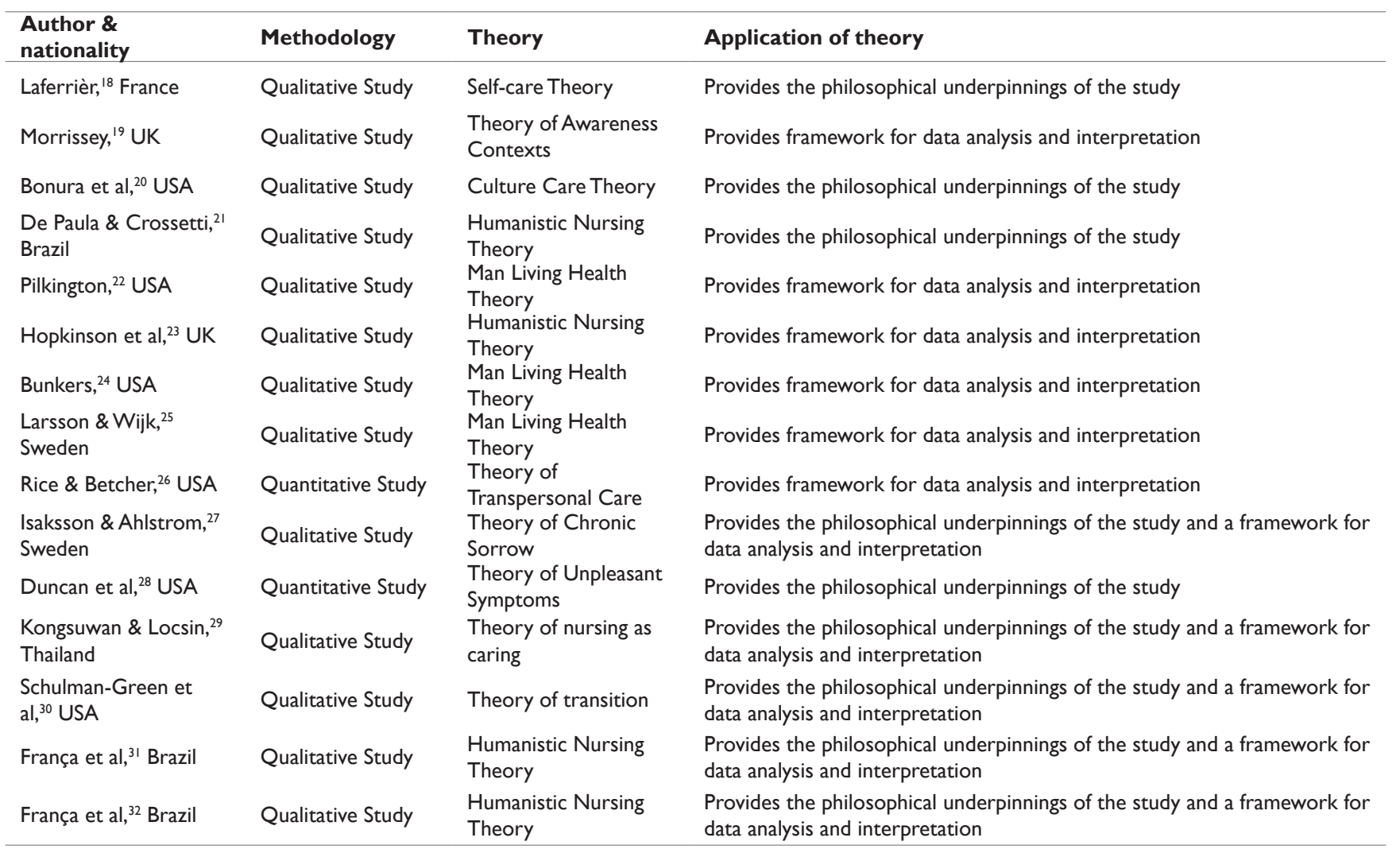


Table 2 Review results distributed by author's country (n; \%)

\begin{tabular}{lll}
\hline Country & $\mathbf{n}$ & $\%$ \\
\hline Brazil & 3 & 20,0 \\
France & I & 6,7 \\
Sweden & 2 & 13,3 \\
Thailand & I & 6,7 \\
UK & 2 & 13,3 \\
USA & 6 & 40,0 \\
Total & 15 & 100,0
\end{tabular}

Table 3 Review results distributed by nursing theories (n)

\begin{tabular}{|c|c|c|c|}
\hline Type of theory & $\mathbf{n}$ & Theory (Author) & $\mathbf{n}$ \\
\hline \multirow{5}{*}{ Grand theory } & \multirow{5}{*}{10} & Culture care theory (M. Leininger) & I \\
\hline & & $\begin{array}{l}\text { Humanistic care theory (J. Paterson \& L. } \\
\text { Zderad) }\end{array}$ & 4 \\
\hline & & Man living health theory (R. Parse) & 3 \\
\hline & & Self-care theory (D. Orem) & 1 \\
\hline & & Theory of transpersonal care (J.Watson) & I \\
\hline \multirow{4}{*}{$\begin{array}{l}\text { Middle-range } \\
\text { theory }\end{array}$} & \multirow{4}{*}{4} & $\begin{array}{l}\text { Theory of awareness contexts (B. Glaser } \\
\text { \& A. Strauss) }\end{array}$ & I \\
\hline & & $\begin{array}{l}\text { Theory of chronic sorrow (G. Eakes, M. } \\
\text { Burke \& M. Hainsworth) }\end{array}$ & I \\
\hline & & Theory of transition (A. Meleis) & I \\
\hline & & $\begin{array}{l}\text { Theory of unpleasant symptoms (E. Lenz, } \\
\text { L. Pugh, R. Miligan, A. Gift \& F. Suppe) }\end{array}$ & I \\
\hline $\begin{array}{l}\text { Conceptual } \\
\text { model }\end{array}$ & 1 & $\begin{array}{l}\text { Theory of nursing as caring (A. Boykin \& } \\
\text { S. Schoenhofer) }\end{array}$ & I \\
\hline Total & 15 & Total & 15 \\
\hline
\end{tabular}

\section{Discussion}

The utilization of nursing theories in palliative care research is uncommon. In fact, although many journals require the identification of a conceptual or theoretic framework on submitted articles, this does not seem to be traditional. ${ }^{33}$ Even so, we admit that some authors may use a nursing theory in their studies and not include this information on the published articles. Regarding the obtained results, we consider that the utilization of a unique nursing theory in palliative care research is not consensual. In spite of that, there is a predominance of grand theories and a trend regarding the utilization of the humanistic nursing theory. This is understandable because this theory share common concepts with the principles of palliative care as relationship, communication, lived experience and suffering. There is also an upward trend of publications after 2005, even though the first article was published in 1995. Curiously, it was in the mid-nineties that some authors began to demonstrate their concern regarding the loss of focus on the development of specific nursing science knowledge as healthcare began to be increasingly provided using an interdisciplinary approach. These authors argued that it was necessary to develop specific nursing research to consolidate the evidence of its importance as an autonomous science and its relevance in an interdisciplinary approach. ${ }^{34-35}$

The distribution of articles by 6 different countries is coherent with the level of development of palliative care provision, presented in 2014 by the World Palliative Care Alliance and the World Health Organization. USA, Sweden, the United Kingdom and France are countries with advanced integration of palliative care in their health care system. Brazil and Thailand are countries with isolated provision of palliative care in their health care system. In spite of that, these two countries have a strong tradition in nursing research. It can be considered that palliative care research using a nursing theory as reference occurs in countries with a more advanced practice in this context. ${ }^{1}$ In terms of methodology, there is a clear predominance of the qualitative approach. This is comprehensive regarding the nature of the studied themes. This kind of approach is frequently considered to be a more holistic and humanized method. Quantitative research emphasizes the quality of entities, processes and their significance instead of quantities, intensities and frequencies. ${ }^{36}$ The fact that four different populations were studied explains the complexity on developing palliative nursing and palliative care research. These populations go through different living experiences and may have different needs that must be studied to improve the quality of care provided.

\section{Conclusion}

The focus of this literature review was on the theoretic base that nurses use in palliative care research. Fifteen articles that specified the utilization of a nursing theory in their investigation were found. Ten different theories emerged and were used in a different manner. The most used type of theory was the grand theory and the most used theory was the humanistic nursing theory. There's a lack of consensus about the utilization of a nursing theory as a framework in palliative care research. Therefore, we consider that the application of different theories in different contexts and populations might contribute to a needed thought and discussion about palliative nursing practice. As a relatively recent area of knowledge, it is necessary to develop more and better research in palliative nursing using a theoretic framework. We also suggest an analysis on the existing palliative care models and their importance to develop and consolidate nursing as a specific discipline in this interdisciplinary context of care.

\section{Funding details}

No funding.

\section{Acknowledgements}

None.

\section{Conflict of interests}

The author declares no conflict of interest.

\section{References}

1. Worldwide Palliative Care Alliance. Global atlas of palliative care at the end of life. London: World Health Organization; 2014. 102 p.

2. World Health Organization. National cancer control programmes: policies and managerial guidelines. Geneva, Switzerland: World Health Organization, 2002. $180 \mathrm{p}$.

3. Radbruch L, Payne S, Bercovitch M, et al. White Paper on standards and norms for hospice and palliative care in Europe: part 1. Eur J Palliat Care. 2009;16(6):278-289.

4. City K, Labyak M. Hospice Palliative Care for the 21st century: A model for quality end-of-life care. In: Ferrell B, Coyle N, editors. 
Oxford textbook of palliative nursing. Oxford: Oxford University Press 2010. 13-52 p.

5. Coyle N. Introducing to Palliative Nursing Care. In: Ferrell B, Coyle $\mathrm{N}$, editors. Oxford textbook of palliative nursing. Oxford: Oxford University Press; 2010. 3-12 p.

6. Krisman-Scott M, McCorkle R. The Tapestry of Hospice. Holist Nurs Pract. 2002;16(2):32-39.

7. Canning D, Rosenberg J, Yated P. Therapeutic relationships in specialist palliative care nursing practice. Int J Palliat Nurs. 2007;13(5):222-229.

8. Reed S. A unitary-caring conceptual model for advance practice nursing in palliative care. Holist Nurs Pract. 2010;24(1):23-34.

9. Johnston B, Smith L. Nurses' and Patients' perceptions of expert palliative care. J Adv Nurs. 2006;54(6):700-709.

10. Bergdahl E, Wikstrom B, Andershed B. Esthetic abilities: a way to describe abilities in expert nurses in palliative home care. J Clin Nurs. 2007;16(4):752-760.

11. Mok E, Chiu P. Nurse-patient relationships in palliative care. $J A d v$ Nurs. 2004;48(5):475-483.

12. Wald F. Forwards to the first edition. In: Ferrell B, Coyle N, editors Oxford textbook of palliative nursing. Oxford: Oxford University Press; 2010.

13. Larkin P. Shaping new thinking in palliative nursing. Int J Palliat Nurs 2007;13(8):364-365.

14. McCloskey J, Maas M. Interdisciplinary Team: The nursing perspective is essential. Nurs Outlook. 1998;46(4):157-163.

15. Lynch M, Dahlin C, Coakley E. Palliative care nursing: defining the discipline?. J Hosp Palliat Nurs. 2011;13(2):106-111.

16. Young A, Taylor S, McLaughlin-Renpenning K. Connections: nursing research, theory and practice. St. Louis, Missouri: Mosby; 2001.

17. Fawcett J. Contemporary nursing knowledge: analysis and evaluation of nursing models and theories. Philadelphia, USA: FA Davis Company; 2005 .

18. Laferriére R. Orem's theory of practice: hospice nursing care. Home Healthc Nurse. 1995;13(5):50-54.

19. Morrissey M. Extending the theory of awareness contexts by examining the ethical issues faced by nurses in terminal care. Nurs Ethics. 1997;4(5):370-379

20. Bonura D, Fender M, Roesler M, et al. Culturally congruent endof-life care for jewish patients and their families. J Transcult Nurs.
2001;12(3):211-220.

21. De Paula C, Crossetti M. O acontecer do cuidado de enfermagem ao ser-criança que convive com AIDS: ser, saber e fazer compartilhado. Rev Gaúcha Enferm. 2005;26(1):102-114.

22. Pilkington F. Grieving a loss: the lived experience for elders residing in an institution. Nurs Sci Q. 2005;18(3):233-242.

23. Hopkinson J, Wright D, Corner J. Exploring the experience of weight loss in people with advanced cancer. J Adv Nurs. 2006;54(3):304-312.

24. Bunkers S. The experience of feeling unsure for women at end-of-life. Nurs Sci Q. 2007;20(1):56-63.

25. Larsson A, Wijk H. Patient experiences of pain and pain management at the end of life: A pilot study. Pain Manag Nurs. 2007;8(1):12-16.

26. Rice E, Betcher D. Evidence base for developing a palliative care service. Medsurg Nurs. 2007;16(3):143-148.

27. Isaksson A, Ahlstrom G. Managing chronic sorrow: experiences of patients with multiple sclerosis. J Neurosci Nurs. 2008;40(3):180-191.

28. Duncan J, Bott M, Thompson S, et al. Symptom occurrence and associated clinical factors in nursing home residents with cancer. Res Nurs Health. 2009;32(4):453-464.

29. Kongsuwan W, Locsin R. Aesthetic Expressions illuminating the lived experience of Thai ICU Nurses caring for persons who had a peaceful death. Holist Nurs Pract. 2010;24(3):134-141.

30. Schulman-Green D, Bradley E, Nicholson N, et al. One step at a time: Self-management and transitions among women with ovarian cancer. Oncol Nurs Forum. 2012;39(4):354-360.

31. França J, Costa S, Lopes $\mathrm{M}$, et al. The importance of communication in pediatric oncology palliative care: focus on humanistic nursing theory. Rev Latino-Am Enfermagem. 2013;21(3):780-786.

32. França J, Costa S, Andrade C, et al. Vivência de Enfermeiros no cuidado à criança em fase terminal: estudo à luz da teoria humanística de enfermagem. Cien Cuid Saúde. 2014;13(3):425-432.

33. Wu H, Volker D. The use of theory in qualitative approaches to research: application in end-of-life studies. J Adv Nurs. 2009;65(12):2719-2732.

34. Beyers M. Is there a future for management? Nurs Manag 1995;26(1):24-25.

35. McCloskey J. The discipline heart of a multidisciplinary team. $J$ Prof Nurs. 1995;11(4):202.

36. Denzin N, Lincoln Y. The sage handbook of qualitative research. 3rd ed. Thousand Oaks:Sage; 2005. 